\title{
The Impact Of Health Card On Citizens' Quality Of Life: Evidence In Bangladesh
}

\author{
Md. Rakibul Hoque \\ University of Dhaka, Bangladesh \\ Dr. Ramiz Uddin \\ Mohammad Mostafizur Rahman Khan \\ Farzana Rahman Shumi \\ Fahmida Sarwar \\ Access to Information (a2i) Programme, \\ Prime Minister's Office, Bangladesh
}

doi: 10.19044/esj.2016.v12n6p369 URL:http://dx.doi.org/10.19044/esj.2016.v12n6p369

\begin{abstract}
People living in the rural areas in developing countries are deprived of the basic needs including health. In Bangladesh, the rural poor people are facing difficulties to be facilitated from the enhanced medical services, mostly because of the increased medical expenses, and the time required to complete the whole process. Henceforth, it is necessary for the government to enhance the medical facilities to its rural citizens for proper development. It has been argued that the health card service system in Bangladesh can enhance the medical services. However, no studies have been conducted to investigate the impact of health card on the quality of life of rural people in Bangladesh. This study attempts to investigate this issue from actual beneficiary perspective. The main objective of this study is to provide a synopsis of the roles of health card on rural citizen of Bangladesh. The data were collected through telephone and face to face interview from a purposive sample in rural community, Bangladesh. The findings show that by using health card service system, rural poor people can get the facilities to visit the doctor directly whereas previously they had to buy ticket and wait for a long time in front of the doctors' room. The result of this study suggests that, by using health card the quality of medical service can be enhanced as well as the time, cost and number of visit can be minimized. The findings of this research will be very useful for policy maker in Bangladesh.
\end{abstract}

Keywords: Health Card, Bangladesh, Quality of Life 


\section{Introduction}

Health service is one of the basic rights of human being. It is an important duty of any government to ensure the better health service to its citizen. For ensuring quality life, it is essential to have improved health service. Better and improved health service indicates the success of a nation (Mason 1990). Therefore for building a successful nation, it is essential for the government to take necessary steps to make better and improve the medical services for the citizens of all classes. Though health is one of the basic needs of human being, many rural people are deprived from getting proper medical treatment due to the increased medical expenses (Starfield 2005). Specially, the poor people in rural areas are mostly affected by this problem because they are more concern about their time and cost.

Bangladesh is a developing country and has about 156 million people, where $85 \%$ of its population live in rural areas (Bangladesh Bureau of Statistics 2014). In rural areas, the literacy rate is very low and many people live under the margin of poverty. That is why, many people are not conscious about their health and safety (Karnani 2006). Though government health service sector is one of the promising sectors for providing medical facilities, most of the time the rural people are not able to receive the facilities as there are many formalities which are required to follow for receiving the services (Kibria 2009). Moreover, it takes more time and visit and sometimes it is very costly. Recently, the Government of Bangladesh has introduced health card systems for providing better facilities to its people, especially rural people.

In health card system, the patients are not required to collect ticket from the ticket counter rather than they can directly go to the doctor's room and discuss about their problems to the doctor. Separate doctors' chambers are assigned to the patients with the health card. Therefore the patients can meet the specialized doctor according to their needs. Only health card holders can get these facilities. The government has already increased their investment in this sector because investing in health card means investing in citizens' quality of life. In this new process there is much promise that the health card will contribute to develop the way of living of the rural people of Bangladesh. Although the health card service system in Bangladesh has significance to enhance the medical service, no studies have been conducted to investigate the impact of health card on quality of life of rural citizens in Bangladesh. This study attempts to investigate this issue from actual beneficiary perspective. The main objective of this study is to provide a synopsis of the roles of health card on rural citizen of Bangladesh and explore whether the modern health card system is better than the traditional or not. 


\section{Literature Review}

Health is the physical condition of being well or being free from disease. It is considered as the overall condition of someone's body or mind. World Health Organization (WHO) provides a definition which says, "Health is a state of complete physical, mental and social well-being and not merely the absence of disease or infirmity." A person having sound health is considered as a healthy person. The level of functional or metabolic efficiency is called health. The Alliance Institute for Integrative Medicine says that, "We view wellness as much more than just a state of physical health. It also encompasses emotional stability, clear thinking, the ability to love, create, embrace change, exercise intuition and experience a continuing sense of spirituality.” According to Business Dictionary.com, it is said that, "Health is a dynamic condition resulting from a body's constant adjustment and adaptation in response to stresses and changes in the environment for maintaining an inner equilibrium called homeostasis." According to Dorland's Medical Dictionary, the definition of health is, "An optimal state of physical, mental and social well-being, not merely the absence of disease or infirmity."

Healthcare is the most important part of our life. People always want to get better and improved facilities from the hospitals. The government of any country also concerns about the enhancement of the medical facilities. In the past a number of researchers have sought to determine the benefits and satisfaction level of the patients for keeping the previous data through health card or any other information technology. Huang et al. (2012) found that people highly desire core-business tools, especially access to medical records and lab results, while discounting hospitals' efforts to connect to social media. For enhancing the safety and quality of health care, it is required to use any technical tools. Simon et al. (2007) argued that adoption rates are lower in smaller practices, those not affiliated with hospitals, and those that do not teach medical students or residents. Interventions to expand EHR use must address both financial and non-financial barriers, especially among smaller practices.

For enriching the quality of health care it has significance to develop health information system. According to Dunnebeil et al. (2012) the perceived importance of standardization and the perceived importance of the current IT utilization were the most significant drivers for accepting electronic health services (EHS) in their practice. Significant influence was shown for the perceived importance of information security and process orientation as well as the documentation intensity and the e-health-related knowledge. When the hospitals keep the regular data of the patients then it becomes easy to have accurate information about the supply of drugs and essential medicines. It also saves time of the patients and doctors. 
For providing improved medical service the government should be conscious about the involvement of users. A considerable amount of literature has been published on this issue. In 'Primary care physician's attitude towards the GERMAN e-Health Card Project, Ernstmann et al. (2009) argued that, user involvement plays a crucial role in the adoption of the German e-health card. Primary care physician's perspective should be represented in the process of developing and designing the technology. Cripps and Standing (2011) provides a number of lessons and insights to improve electronic records adoption projects in Ngaanyatjarra region. The limited resources and limited choices faced by the region lead to the development of a number of key approaches that revolved around aiming for a workable system rather than a high-end flawless solution. This ethos pervaded the electronic health records project and was underpinned by a patient centered approach and a strong desire to improve the service given to patients.

Most of the time the insolvent people are not encouraged to go to the hospitals because of increasing medical cost, various formalities, visits for more than one time and so on. Recently investigators have examined the effects of these factors on the patients in order to take the medical services. Price et al. (2013) suggest that both older and younger adults would deem a PHR useful if it provides memory support in the form of reminders, provides tools to aid in comprehension of one's health concerns, is interactive and provides automatic functions, and is highly accessible to authorized users, yet one's information is kept secure and private.

Bangladesh is a developing country. Here, the rural people are living under the poverty margin. Because of highly increasing of essential medical cost, many rural people are being discouraged for taking proper medical service. A study was conducted on the citizens of Wazirpur, Barisal. It is found that, in the traditional system, the patients of Wazirpur had to go 25 $\mathrm{km}$ for the medical treatment at Barisal Zilla Hospital. Then they had to buy a ticket from hospital counter by paying tk. 5 . Afterwards they are required to wait for a long time in front of the doctor's room and for receiving the service. With the aim of providing better and improved health services, Wazirpur Upazilla Health Complex which is situated in Barisal has introduced a new service that is health card for its service recipients. This study was conducted to assess the TCV of health card services.

\section{Objective of the Study}

The aim of this paper is to provide a cost-benefit analysis of health card systems. Both of the monetary and non-monetary benefits of the health services were included in our investigation. This study also explored the 
satisfaction as well as perception of user regarding health card system. The specific objectives of the study were:

- To determine the time and cost level after getting extra facilities in health services.

- To evaluate the number of visit after introducing extension facility of health service.

- To analyze the satisfaction and perception level of service recipient.

\section{Methodology}

This study was exploratory in nature where we analyzed cost, benefit and utility level of individual through using quantitative technique that provides an opportunity to uncover the information from the deep of minds of the respondents using phone interviews, face-to-face interviews, and indepth interviews from different groups of respondents. The study was based upon primary data. However, the secondary data was reviewed to progress our findings. The secondary data helped us to develop our study in a procedure or sequence. First of all we identified the problem, then comprehend the situation and defined the problem statement of our project. And finally this procedure helped us to access to relevancy, efficiency and effectiveness of the intervention.

The citizens from Wazirpur upazilla in Barisal area were considered as a study population. Wazirpur upazilla of Barisal is 248.36 square kilometers in area and its total population is 51597 (Bangladesh Population Census, 2011). Administratively, it consists of one upazilla 9 unions, where there are 123 Villages. In medical facilities, there are health complex, nine family planning centers and four satellite clinics in Wazirpur upazilla. This study has been conducted among those who received the medical service from Wazirpur upazilla health complex using health card under this pilot project.

A total of 161 beneficiaries were interviewed to this study. Data of this study were collected in two ways, like- telephone interview and face to face interview. Out of 161, 75 (47\% of total interviews) were conducted through telephone and 86 (53\% of total interviews) of them were conducted by face to face interviews. So among 161 interviewers $100 \%$ were conducted in our survey. According to this survey, among the interviewees, most of them (62\%) were females, whereas the males are comparatively less (38\%) in number.

The respondents were asked about the health services to identify the differences between the ticket system service and the health card service. Mainly we asked the question in such a way as if we can easily analyze the time, cost and visit about taking health service by using health card. 
Generally it is a cost benefit analysis about digital health card system. In particular, researcher asked the following questions to the respondents:

- How much time needs to take the services?

- What is the cost for services?

- How many times the patients visit to the health service center?

- Are the respondents satisfied?

Besides, we encouraged them to be frank with us to tell their actual information we asked another question that "What is respondent's suggestion for getting more developed health service?” Predominantly, data analyses was started with a brief about the facilities of digital health services as if they feel interested about our study and would like to help us to reach our goal. Data were analyzed using SPSS software (IBM, v22). The researchers reviewed, edited and cleaned the data by performing a series of frequency and data range checks. Any inconsistencies were checked visually by comparing the electronic entry to the entry on the original questionnaire.

\section{Result}

The results from the field research are presented in this section. We treat participants' statements as "proof of concept". We believe the reliability of our interpretations is reinforced through the provision of statements from many participants, whether these are unique or common within and between different groups of respondents.

\section{TCV Analysis}

The study was conducted with a view to assess the amount of time, cost and visit saved on average for a single service taken by the respondents who use the health card service. From the analysis of the collected data, we can measure the TCV (time, cost and visit).

Required Time and Cost for getting service

From the analysis, it is shown that $94 \%$ of the service receivers required for spending about 5 hours to get service using health card, whereas only $2 \%$ of them required to spend more than 10 hours. On the contrary, $88 \%$ of the 


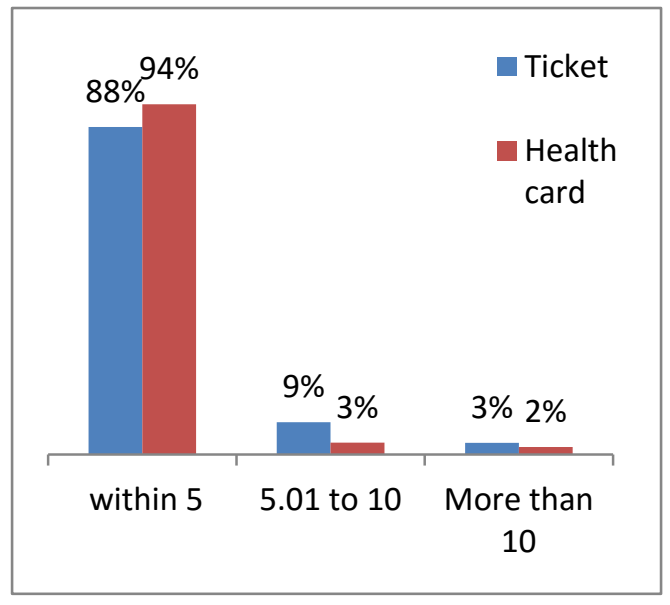

Figure 1: Time Required for getting service

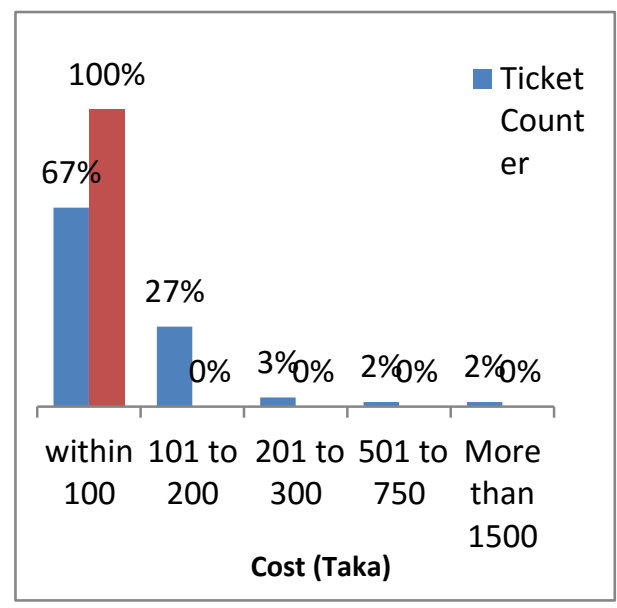

Figure 2: Cost required for getting service

ticket service receivers spent 5 hours or less on average and $3 \%$ of them spent more than 10 hours to get the health services.

Throughout this paper it is found a comparative analysis on the cost needed for receiving a single medical treatment through the ticket counter and the health card service. All the respondents who had used the health card service had to spent BDT 100 or less on average for taking medial service. On the contrary, people who received services through the ticket counter, among them 67\% service receivers had to spend more than BDT 100. This chart also gives the notion that, $27 \%$ of the interviewees had to pay 200 taka at the same time and others (7\%) had to pay more than 200 taka to take a single medical facility from the ticket counter service while none of the recipients using the health card service needed to pay more than 100 taka.

\section{Required visit for getting service}

According to the collected data it is observed that $93 \%$ of the respondents stated that it took a single visit and $7 \%$ of the respondents mentioned that it took 2 visits to get a single health service using the health cards. On the other hand, $88 \%$ of the respondents claimed that they had needed one visit and 


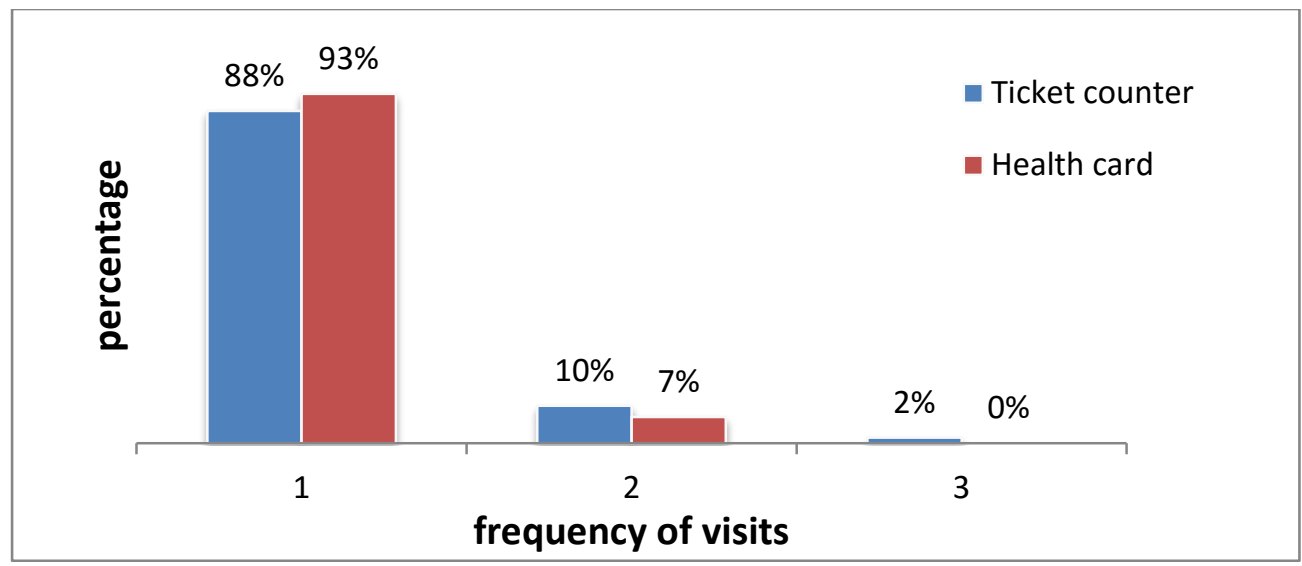

Figure 3: Required visit to get service using ticket and health card

$10 \%$ had needed 2 visits to take a single medical service through the ticket counter. From this research it is clearly found that the introduction of the health card service is very helpful for the service seekers because it takes less time, cost and distance to travel.

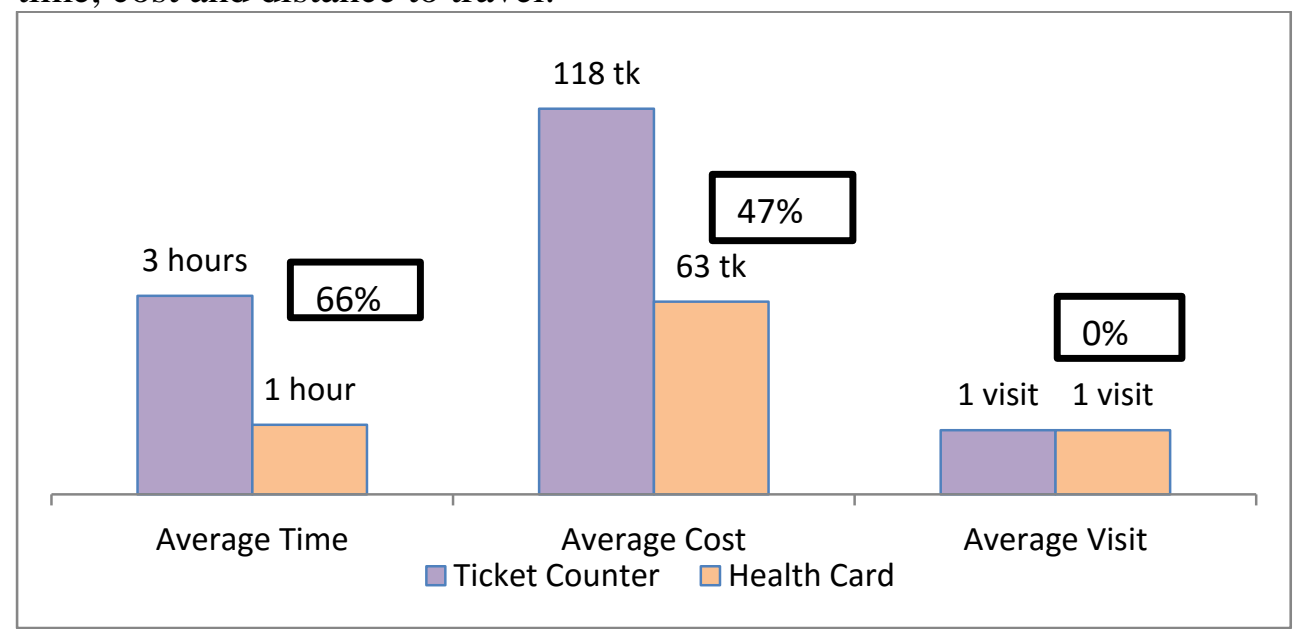

Figure 4: Average Time, Cost and Visit

The given figure shows the experimental data on TCV (time, cost and visit) which are required for getting a single medical treatment. It revealed that, the health card service is very much successful to lessen the average time and cost. It shows that new system of health cards has reduced average time to $66 \%$ comparing the legacy ticket counter system. Which indicates that ticket counter service took more than double time in comparison to that of the health card service system. It also shows that average cost has been reduced to $47 \%$ by replacing system. Thus, the average cost is reduced to almost half than that of the earlier time, although when it comes to the issue of required average visit, it remains the same. 


\section{TCV+ Analysis}

As this study provides a TCV+ study on the services, it also focused on other non-monetary benefits like service providers' behavior, beneficiaries' satisfaction level and other aspects regarding the health card system. Concerning this issue, study revealed that health card service is more appropriate comparing to the ticket counter service to get/in getting a medical treatment. For better understanding of non-monetary benefits, the study scrutinized the advantages and disadvantages of health card service system. Then the study went through the disadvantages of ticket counter system. Thereafter, the study evaluated the satisfaction of beneficiaries and the reasons of their satisfaction. The study represents the results obtained from the analysis of TCV, where it is found that respondents, receiving service from the health cards, mentioned the reasons as following:

According to them, the health card facility is taking less time, less cost and providing effective solutions. The health card service is not only lessening time (28\%), cost (19\%) and visit (18\%), but also lessening labor (14\%), harassment (10\%), transport (5\%) and tension $(4 \%)$ in a visible number.

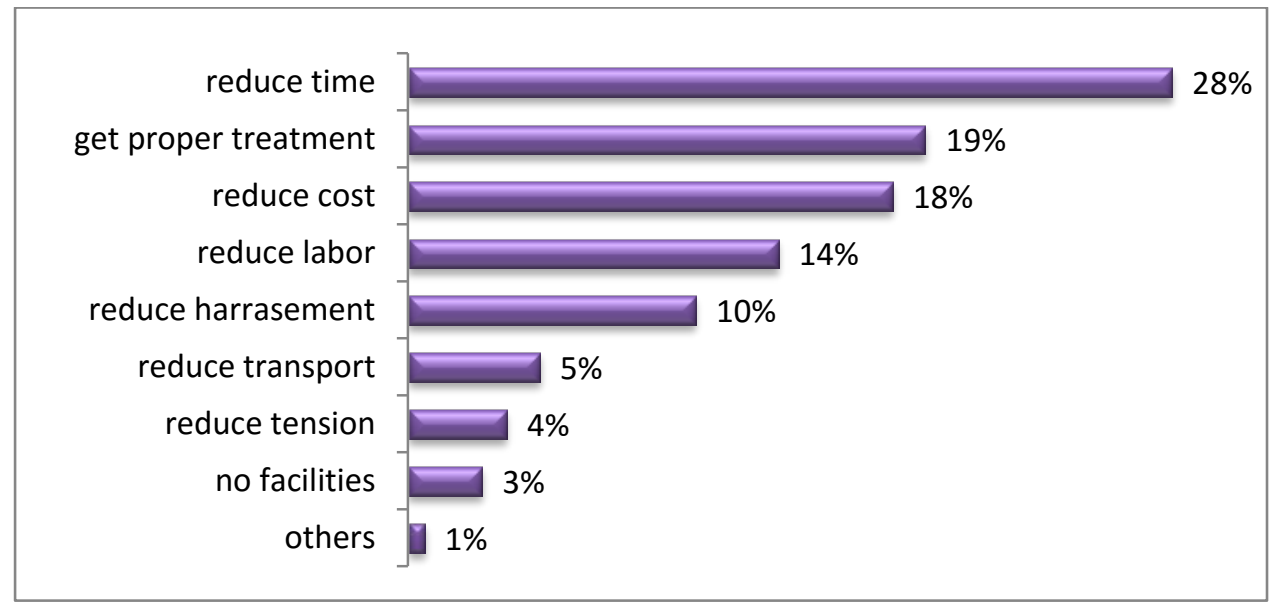

Figure 5: Advantages for receiving service using health card

\section{Level of satisfaction}

The study revealed, as shown in figure 6, people who received health service through health cards are mostly satisfied (64\%) with the health service providers. It also revealed that, $14 \%$ and $13 \%$ of informants were very much satisfied and moderately satisfied respectively with the health card service. In contrast, only $6 \%$ and $2 \%$ of beneficiaries expressed dissatisfaction with the new service of health card. Figure 7 provides the information about the most important reason behind the satisfaction level are 'examine with importance' and 'less cost' and the percentages of people satisfied for those reasons were 33\% and 31\% respectively. In case of 
satisfaction, less cost consumption and free medicine facility were the others main satisfactory factors in health card service.

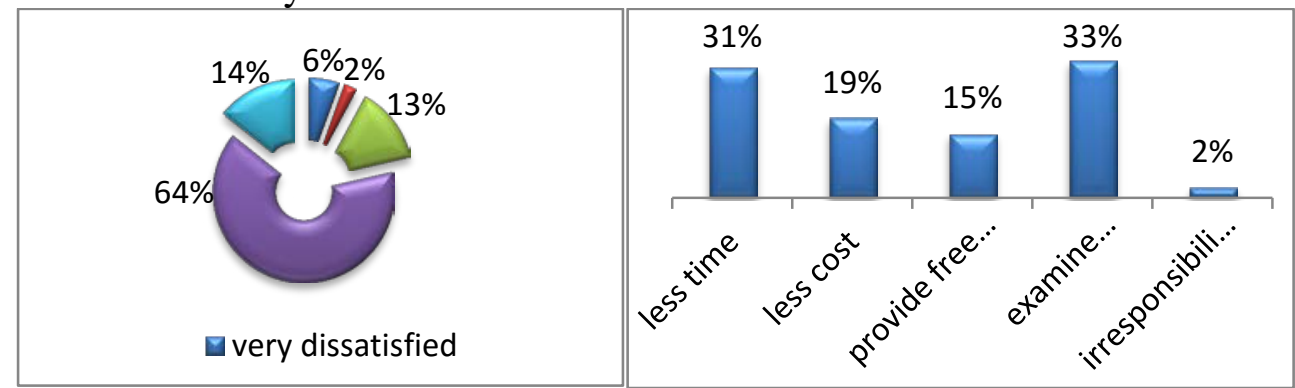

Figure 6: Satisfaction level of health card service

Figure 7: Reasons of satisfaction level

\section{Hypothesis Testing}

Ho : $\mu_{\mathrm{hc}}=\mu_{\mathrm{nhc}}$ against Ha $: \mu_{\mathrm{hc}}<\mu_{\mathrm{nhc}}$ where,

$\mu_{\mathrm{hc}}=$ average time of those who have health card

$\mu_{\text {nhc }}=$ average time of those who have not health card

Table 1: Independent Sample t-test

\begin{tabular}{|c|c|c|c|c|c|c|}
\hline & \multirow[b]{2}{*}{ t-value } & \multirow{2}{*}{$\begin{array}{r}\text { Degree o } \\
\text { freedom }\end{array}$} & \multirow{2}{*}{$\begin{array}{c}\text { Significance } \\
\text { level }\end{array}$} & \multirow[b]{2}{*}{ Mean Differen } & \multicolumn{2}{|c|}{$\begin{array}{l}\text { 95\% Confidence } \\
\text { Interval of the } \\
\text { Difference }\end{array}$} \\
\hline & & & & & Lower & Upper \\
\hline $\begin{array}{l}\text { average time of those } \\
\text { who have health card }\end{array}$ & 10.747 & 113 & .000 & 1.49589 & 1.2201 & 1.7717 \\
\hline $\begin{array}{c}\text { average time of those } \\
\text { who have not health } \\
\text { card }\end{array}$ & 14.218 & 126 & .000 & 3.09096 & 2.6607 & 3.5212 \\
\hline
\end{tabular}

The significance (2-Tailed) value in our study is 0.00 . This value is less than .05. Because of this, we can conclude that there is a statistically significant difference between the two groups. Since our Group Statistics box revealed that the Mean for the time those who have not health card was greater than the Mean for the time those who have health card, we can reject the null hypothesis.

\section{Test of Association}

Ho: There is no association between incomes levels of the respondent by health card received at home through health worker.

Ha: There is association between incomes levels of the respondent by health card received at home through health worker.

Significance level: let our significance level be 0.05 . From the above chi-square table we can see that the p-value for Pearson Chi-Square $=0.007<$ .05. Hence our null hypothesis is rejected. So, we can conclude that, there is 
an association between incomes levels of the respondent by health card received at home through health worker.

\section{Case II:}

Ho: There is no association between Age groups of the respondent by getting health card through home visit.

Ha: There is association between Age groups of the respondent by getting health card through home visit.

Significance level: let our significance level be 0.05 . From the above chi-square table we see that the $\mathrm{p}$-value for Pearson Chi-Square $=0.04<.05$. Hence our null hypothesis is rejected. So, we can conclude that there is an association between Age group of the respondent by getting health card through home visit.

\section{Limitations and Future Direction}

Although the research has reached its destination, there were some limitations. Several questions remain unanswered at present. First, the study conducts in only one developing country. To ensure well findings, future research should use wide-ranging samples drawn from a number of developing countries. Second, the researchers faced several challenges in case of getting contact numbers from service providers, willingness to response over phone and proper cooperation during face to face interviews. Further studies on the current topic, which take these variables into account, will need to be undertaken.

The paper has recommended that there is still necessity for improving the health card service. It suggests, the hindrance related to the health card service should be reduced. The following recommendations may contribute in this regard:

\begin{tabular}{|c|c|}
\hline Recommendations & Responsible authority \\
\hline $\begin{array}{c}\text { Adequate number of doctors to be vested with the health card } \\
\text { services. }\end{array}$ & $\begin{array}{l}\text { Wazirpur health } \\
\text { complex }\end{array}$ \\
\hline $\begin{array}{c}\text { The program can cover more areas as well as beneficiaries under } \\
\text { health card service. }\end{array}$ & $\begin{array}{l}\text { Wazirpur health } \\
\text { complex }\end{array}$ \\
\hline $\begin{array}{c}\text { An appropriate publicity campaign should be launched to popularize } \\
\text { this new system. }\end{array}$ & $\begin{array}{l}\text { Wazirpur health } \\
\text { complex }\end{array}$ \\
\hline Develop more beneficiary friendly health card service system. & $\begin{array}{l}\text { Wazirpur health } \\
\text { complex }\end{array}$ \\
\hline $\begin{array}{c}\text { The Health Complex should be provided with sufficient equipment } \\
\text { and medicines. }\end{array}$ & $\begin{array}{l}\text { Ministry of health and } \\
\text { family welfare. }\end{array}$ \\
\hline
\end{tabular}

\section{Conclusion}

Health service is a basic human need as well as it is considered as a public right. The government of Bangladesh is providing this basic need through ticket counter. But health care is a special type of good and demand 
of health is inelastic. So, when individual needs to have health service, then it is mandatory for him to take it. As most of the people of Bangladesh are poor, they cannot take this service privately. Although the government of Bangladesh is providing this service through ticket system, it is more time consuming and costly. Therefore, special health service can contribute to overcome this problem. Our research study is based on health service which deals with health card system. Recently, government has introduced health card services for the wellbeing of the people of Wazirpur upazilla at Barisal. The present study was designed to determine the effect of using the digital health card services. This study found that health card system is more effective than ticket system. It is explored that introduction of special health services has minimized the time, cost, number of visits and excessive work. By using health card, individuals can easily maximize their utility with minimum cost:health card system requires less time, cost and visit (TCV) and it provides better outcome and better services. If we explain it economically, this reduction of time, cost and number of visits help them to engage in another work. So, they can improve their output, maximize their profit and remain at the higher utility level. It influences the satisfaction level of an individual, which is most prominent element of human nature. And it helps to bring a betterment of socio-economic condition of a country. It can be drawn from the present study that the health card services satisfy the needs of poor people and it has a great impact on socio-economic condition of the country. The evidence of the study suggests that for better service, the extension of health care facility should be strengthened according to the satisfaction level of health card holder. In addition, adequate skilled doctors, equipment and medicine will be required. Moreover, government must be accountable and transparent in case of providing this extended health care facility.

\section{Acknowledgements}

This work was supported by Government of Bangladesh, UNDP and USAID. The authors, therefore, gratefully acknowledge their technical and financial support.

\section{References:}

Bangladesh Bureau of Statistics (2014) Population Census Report, 2014. Bangladesh Bureau of Statistics.

Cripps, H., \& Standing, C. (2011). The implementation of electronic health records: A case study of bush computing the Ngaanyatjarra Lands. International journal of medical informatics, 80(12), 841-848.

de Veer, A. J., Peeters, J. M., Brabers, A. E., Schellevis, F. G., Rademakers, J. J., \& Francke, A. L. (2015). Determinants of the intention to use e-Health 
by community dwelling older people. BMC health services research, 15(1), 103.

Deng, Z., Mo, X., \& Liu, S. (2014). Comparison of the middle-aged and older users' adoption of mobile health services in China. International journal of medical informatics, 83(3), 210-224

Dorland, W. A. N. (1980). Dorland's medical dictionary. Saunders Press.

Dünnebeil, S., Sunyaev, A., Blohm, I., Leimeister, J. M., \& Krcmar, H. (2012). Determinants of physicians' technology acceptance for e-health in ambulatory care. International journal of medical informatics, 81(11), 746760.

Ernstmann, N., Ommen, O., Neumann, M., Hammer, A., Voltz, R., \& Pfaff, $H$. (2009). Primary care physician's attitude towards the GERMAN e-Health Card Project-Determinants and Implications. Journal of medical systems,33(3), 181-188

Hage, E., Roo, J. P., van Offenbeek, M. A., \& Boonstra, A. (2013). Implementation factors and their effect on e-Health service adoption in rural communities: a systematic literature review. BMC health services research, 13(1), 19.

Hoque, M. R., \&Bao, Y. (2015). Cultural influence on adoption and use of eHealth: evidence in Bangladesh. Telemedicine and e-Health, 21(10), 845-851.

Huang, E., Angela Chang, C. C., \& Khurana, P. (2012). Users' preferred interactive e-health tools on hospital web sites. International Journal of Pharmaceutical and Healthcare Marketing, 6(3), 215-229.

International Health Conference, New York, 19-22 June, (1946)

Jen, W. Y., \& Hung, M. C. (2010). An empirical study of adopting mobile healthcare service: The family's perspective on the healthcare needs of their elderly members. Telemedicine and e-Health, 16(1), 41-48.

Jung, M. L., \& Loria, K. (2010). Acceptance of Swedish e-health services. Journal of Multidisciplinary Healthcare, 3, 55.

Karnani, A. G. (2006). Mirage at the Bottom of the Pyramid.

Kibria, M. (2009). Problems and Prospects of Garments Sector in Bangladesh-an Overview in the Context of Recent Global Recession (Doctoral dissertation, East West University)

Mason, J. O., \& McGinnis, J. M. (1990). "Healthy People 2000": an overview of the national health promotion and disease prevention objectives. Public Health Reports, 105(5), 441.

Nuq, P. A., \& Aubert, B. (2013). Towards a better understanding of the intention to use eHealth services by medical professionals: The case of developing countries. International Journal of Healthcare Management, 6(4), 217-236 
Price, M. M., Pak, R., Müller, H., \& Stronge, A. (2013). Older adults' perceptions of usefulness of personal health records. Universal access in the information society, 12(2), 191-204.

Saracci, R. (1997). The World Health Organisation needs to reconsider its definition of health. Bmj, 314(7091), 1409.

Simon, S. R., Kaushal, R., Cleary, P. D., Jenter, C. A., Volk, L. A., Poon, E. G., ... \& Bates, D. W. (2007). Correlates of electronic health record adoption in office practices: a statewide survey. Journal of the American Medical Informatics Association, 14(1), 110-117.

Starfield, B., Shi, L., \& Macinko, J. (2005). Contribution of primary care to health systems and health. Milbank quarterly, 83(3), 457-502.

Whetstone, M., \& Goldsmith, R. (2009). Factors influencing intention to use personal health records. International Journal of Pharmaceutical and Healthcare Marketing, 3(1), 8-25.

Woodward, A., Fyfe, M., Handuleh, J., Patel, P., Godman, B., Leather, A., \& Finlayson, A. (2014). Diffusion of e-health innovations in 'postconflict'settings: a qualitative study on the personal experiences of health workers. Human resources for health, 12(1), 22. 